\title{
Los (des)bordes del archivo. Afectos, ética y representación histórica en las poéticas testimoniales de Albertina Carri
}

\section{The Boundaries of the Archive. Affections, Ethics and Historical Representation in the Testimonial Poetics of Albertina Carri}

\author{
Lucas Gerardo Saporosi \\ CONICET/UBA/UNLP \\ lucas.saporosi@gmail.com
}

\section{Resumen}

Tomando como punto de partida la discusión entre Ann Cvetkovich (2003) y Sara Ahmed (2004 [2015]) sobre la idea de archivo, pretendemos delimitar una forma particular de la práctica archivística que tome en consideración a las dimensiones ética y afectiva como fundamentales en su conceptualización y que contribuya a revisar la idea misma de representación histórica y del estatuto de documento archivable. Para hacerlo, nos proponemos explorar una serie de producciones estéticas de Albertina Carri -Restos (2010), Operación Fracaso y el Sonido Recobrado (2015) y Cuatreros (2017) - con el objetivo de indagar críticamente sobre los modos de delimitar un archivo de este tipo y especificar su registro documental, atendiendo a recuperar el lugar contingente de la experiencia, del territorio y de la construcción de memoria sobre el pasado reciente argentino.

Palabras clave: Archivo, afectos, ética, pasado reciente.

\section{Abstract}

Taking as a standpoint the discussion between Ann Cvetkovich (2003) and Sara Ahmed (2015) regarding the idea of the archive, we pretend to delimit a specific form of the archival practice which considers ethical and affective dimensions and to contribute to revise the notion of historical representation and the statute of archival documents. To do so, we propose to explore a series of aesthetical productions of Albertina Carri-Restos (2010), Operación Fracaso y el Sonido Recobrado (2015) and Cuatreros (2017)—with the objective of inquiring on the ways in which she builds the archive and conceives the documents, attending to recover the role of experience, territory and memory over Argentinian recent past.

Keywords: Archive, affections, ethics, recent past. 


\section{Introducción}

A casi diecisiete años de su estreno, Los Rubios se ha convertido en una de las producciones estéticas más analizadas en el campo de estudios sobre la memoria y el pasado reciente y sobre la que han versado una pluralidad de voces y posicionamientos en torno a la reconstrucción de la experiencia militante de los setenta. Albertina Carri ha configurado una práctica poético-testimonial, usando el concepto de Ana Amado (2009), que ha puesto en tensión un nudo problemático fundamental en la reflexión intelectual sobre la construcción de la memoria: la cuestión de la representación de esos acontecimientos.

Georges Didi-Huberman, en Imágenes pese a todo (2004), se ha hecho la pregunta acerca de si determinados eventos históricos pueden o no ser considerados "irrepresentables" o "inimaginables", atendiendo a contribuir al debate surgido luego de la Segunda Guerra Mundial en el campo de las ciencias sociales y de la filosofía de la historia. El autor se ha orientado a discutir esta imposibilidad de elaborar imágenes y palabras al respecto de estos acontecimientos y ha buscado, por el contrario, asumir la capacidad de arrebatarle la visualidad a los hechos históricos, por más inauditos que estos hayan sido. Esas imágenes y discursividades, no obstante, no se han presentado como condensaciones de la verdad histórica, sino como "jirones" de esta, vestigios e instantes de verdad. Por tanto, la capacidad de construir sentidos sobre ella, aún en lo intolerable de la imagen del horror y aún en la fragmentación del recuerdo, resulta ser una tarea posible y necesaria.

Frente a ciertas tesis que han sostenido el estatuto de la irrepresentabilidad, nuestra mirada sobre las prácticas poético-testimoniales realizadas por hijos e hijas de militantes de los años sesenta y setenta en Argentina asume que las experiencias de memoria son efectivamente capaces de hacer emerger encuentros imprevistos con los recuerdos y con las figuras de los familiares a partir de patrones híbridos de temporalidad e iluminar ciertos instantes de verdad en zonas oscuras no percibidas en otros momentos de la reconstrucción. En este sentido, la capacidad de arrebatar visualidades a una experiencia intolerable revitaliza la dimensión ética de la representación, ya no entendida como mera reproducción, sino como un desplazamiento inmanente y performativo sobre la escena de memoria.

Luego de Los Rubios, Carri realizó una serie de películas de ficción que no estuvieron específicamente centradas en la cuestión de la memoria sobre la desaparición de su padre y madre, pero sí mantuvieron ciertas modalidades estéticas y ciertos ejes temáticos recurrentes, como aquellos asociados al dispositivo familiar, la cuestión de los afectos y las expresiones de la violencia. ${ }^{1}$ En 2010, la directora produce un retorno a su experiencia de memoria con el cortometraje Restos, producido en el marco

1 Las películas a las que se hace referencia son: Géminis (2005), Urgente (2007) y La rabia (2008). 
del proyecto 25 miradas, 200 minutos e impulsado por la Secretaría de Cultura de la Nación con motivo de la conmemoración del bicentenario. En 2015, esa exploración toma la forma de una instalación audiovisual realizada en la Sala PAyS en el Parque de la Memoria y bajo el nombre Operación fracaso y el sonido recobrado. Y, en 2017, el registro de su biografía derivó en el documental Cuatreros.

Asumimos esta constelación de poéticas sobre la memoria como un intento de construcción de una forma singular de archivo a partir de la cual la materialidad de los recuerdos adquiere diferentes modos de traducción y de visibilización documental. Así, en el transcurso de estas producciones, Carri genera nuevas entradas o escenas a ese archivo y, con ellas, nuevas indagaciones sobre su pasado y nuevos contactos con esa materialidad. Como ella misma sugiere:

En esa búsqueda de rincones poco transitados me encontré pensando en la materialidad de la historia, en los restos materiales como biografía de una época y en la memoria material que significa una película. La historia está escrita, basada, memorizada y relatada a partir de restos materiales; los documentos en que se inspira la épica del relato histórico (2010).

En este sentido, ¿cómo pensar ese archivo? ¿Bajo qué criterio temporal? ¿Bajo qué forma del documento? Estas preguntas orientarán el presente trabajo y, en lugar de respuestas acabadas, se intentará producir una serie de reflexiones sobre el cruce entre la práctica estética y la noción de archivo en el marco del campo de estudios sobre la memoria.

\section{Una genealogía de la noción de archivo}

Si la noción de archivo puede configurar una zona de encuentro entre la filosofía del arte y las disciplinas sociohistóricas, se debe a una reelaboración articulada que han desarrollado tanto las ciencias sociales como los/as artistas y activistas contemporáneos de los preceptos de Michel Foucault y Jacques Derrida sobre la práctica archivística.

Esta genealogía propone un corrimiento que se desplaza de aquel imaginario del repositorio oficial de documentos a una noción de archivo más amplia y dinámica, que tensiona sus propios límites y funciones.

El dilema de Foucault por el cual un archivo supone, ante todo, "la ley de lo que puede ser dicho y el sistema que rige la aparición de los enunciados" (cit. en Castro 22) trae consigo una encrucijada que puede describirse a través de la tensión entre su pretensión de totalidad y los efectos de los entramados sociales en el campo de las disputas por la aparición pública del sentido. Esta tensión es la que recupera Derrida al hablar de mal de archivo, insistiendo en la implicancia de una pulsión que aspira a conservarlo todo pero que choca con "la lógica de la finitud y de los límites fácticos" de la institución archivo. Tanto en Foucault como en Derrida, la propuesta conduce 
a una forma del archivo en la cual su existencia se sostiene redefiniendo sus límites y la ontología de sus documentos.

Específicamente Derrida —en su argumentación a través del exergo de la circuncisión - indagó en la dimensión corporal y epidérmica de los documentos y sus efectos, asumiendo el complejo entramado de temporalidades que subyacen a la práctica de quien desarrolla la tarea de archivista. ${ }^{2}$

Esta genealogía de la noción de archivo resulta fundamental para pensar sus apropiaciones contemporáneas en el campo del arte. En este marco, Hal Foster ha sugerido pensar la recurrencia a explorar e intervenir los archivos como un "impulso" singular y propio de esta época, a partir del cual ciertas/os artistas han orientado sus intervenciones produciendo rupturas en cadenas de significados y rearmando nuevas formas de articular el sentido de los documentos.

En este cruce entre arte y documentos, la historiadora española Ana María Guasch inscribe en este recorrido a las "dos grandes máquinas" del archivo y del montaje visual durante la primera parte del siglo xx: por un lado, el Libro de los pasajes de Walter Benjamin y Atlas Mnemosyne de Aby Warburg; y por el otro, los archivos fotográficos de August Sander, Karl Blossfeldt y Albert Renger-Patzsch. Al analizar estos casos en particular, la autora pone el foco en la relación entre la obra de arte, el archivo y la memoria. Guasch plantea que "la obra de arte considerada en tanto que archivo" demuestra que el trabajo con los documentos en la configuración de una intervención artística evidencia la posibilidad de múltiples selecciones y recombinaciones para "crear una narración diferente, un nuevo corpus y un nuevo significado dentro del archivo dado" (2).

El procedimiento de montaje resulta fundamental en esta tarea, y constituye no solo una técnica de combinar documentos, sino también una operación de la hermenéutica sobre esos mismos registros. Esto implica que en la misma práctica de reconstruir cadenas de sentidos, también se produce una interpretación de los documentos; aquello que Derrida esbozó con la tensión entre la función arcóntica y el poder de consignación del archivo.

Tomando como punto de partida los trabajos de Benjamin, Warburg, Sander, Blossfeldt y Renger-Patzsch, Guasch incorporó una cualidad fundamental para vincular la memoria y el archivo: la práctica de inscripción. Así, la experiencia de reconstruir una serie de eventos del pasado requiere de una determinada superficie para desplegarse e inscribirse, sea territorial, discursiva y/o imaginariamente, que a la vez se ve condicionada por determinados marcos sociales, históricamente situados y atravesada por la experiencia de la comunidad de donde surge.

2 Este cruce se analiza con mayor profundidad en Saporosi, "Implicancias epistemológicas y reflexiones metodológicas en torno a la construcción de un archivo afectivo". 


\section{La construcción de un archivo afectivo}

A partir de esta genealogía, se puede considerar la idea de un archivo afectivo. ${ }^{3}$ En efecto, esta serie de formulaciones nos otorgan el fundamento para extender nuestra concepción sobre la ontología de los documentos y sobre los límites del archivo. Por tanto, ¿pueden, por ejemplo, las expresiones artísticas de carácter efímero, como una instalación o una performance, y/o los territorios cotidianos de la comunidad constituirse como registros de un archivo? ¿Pueden los afectos construir series analíticas a partir de estos documentos? ¿Qué implicancias éticas se inscriben en la construcción de este tipo de archivo?

La discusión entre Ann Cvetkovich y Sara Ahmed nos resulta pertinente para reflexionar sobre estas inquietudes.

El aporte de Cvetkovich propone la construcción de un "archivo de sentimientos" basado en "una exploración de textos culturales como depósitos de sentimientos y emociones que son codificados según, no sólo el contenido de los textos mismos, sino también, de las prácticas que giran alrededor de su producción y recepción" (7).

A través de esta configuración, la autora se orienta a interrogar el concepto de lo público y revisa su constitución en torno a qué vidas y qué prácticas son efectivamente dignas de archivarse e institucionalizarse en un proceso de conservación público. En este sentido, un archivo de este tipo opera otorgando inteligibilidad a las diferentes formas y estrategias de supervivencia que desarrollan y han desarrollado grupos desplazados, minoritarios o violentados de la esfera pública.

Sara Ahmed, por su parte, revisa la noción de "archivo de sentimientos" de Ann Cvetkovich partiendo de un abordaje distinto de los afectos en los procesos de rememoración. Ahmed lee críticamente la capacidad y posibilidad de un archivo de albergar sentimientos y emociones, como si aquellos pudiesen convertirse en depósitos afectivos y en propiedad de los materiales documentales. Para la autora, los afectos no "están en" el archivo ni se encuentran disponibles en los materiales; por el contrario, según la autora, "éstos circulan y generan efectos a partir de las palabras y las prácticas que nombran y aluden a sentimientos" (19). Los afectos configuran superficies de legibilidad sobre los archivos y, desde esta perspectiva, pueden conformarse bajo la idea de una "zona de contacto" (20). Afirma la autora:

Un archivo es efecto de múltiples formas de contacto, incluyendo las institucionales (con bibliotecas, libros, sitios de internet), así como formas cotidianas de contacto (con amigos, familias, otros). Algunas formas de contacto se presentan y autorizan a través de la escritura (y están enlistadas en las referencias),

3 Para un desarrollo más profundo de la idea de archivo afectivo ver Saporosi, "La experiencia del amor en las producciones estéticas de hijos e hijas de militantes detenidos/as desaparecidos/as: La construcción de un archivo afectivo". 
mientras que otras formas de contacto no van a estar, serán borradas, aunque puedan dejar la huella (20).

Se podría afirmar, entonces, que del contacto emergen los sentimientos, y no viceversa. Así, los archivos comprendidos como zonas de contacto se transitan y se experimentan en sus múltiples dimensiones; un archivo, desde esta perspectiva, puede constituirse, por ejemplo, a partir de un paisaje urbano o en un espacio comunitario, signado por las marcas de esa comunidad. Sus documentos no son solo materiales tangibles, sino también rastros, marcas, vestigios y/o voces que recuperen experiencias pasadas, intervenciones y performances espontáneas, pasajeras y efímeras (Saporosi, "Implicancias epistemológicas"). Por esta razón también pueden conformarse como territorios de memoria, utilizando en el concepto de Ludmila da Silva Catela. En sintonía con Arlette Farge, para quien "el archivo hace aparecer escenas de la historia y a partir de ellas, reflexiona" (23), estas zonas de contacto posibilitan la construcción de historias y experiencias afectivas que permiten ser recuperadas, reconstruidas o rearticuladas a través de operaciones hermenéuticas singulares.

Para resumir nuestras ideas, el archivo afectivo que proponemos aquí supone:

a) Un abordaje amplio de la noción de documento en la que coexisten múltiples temporalidades y formas de aparición.

b) Un trabajo de registro y de reconstrucción sociohistórica donde la interpretación de esos documentos se hace sobre la base de una operación hermenéutica, donde el montaje y la construcción de escenas resultan fundamentales.

c) Una escena de contacto con esos documentos que delimita una determinada superficie afectiva y condiciona la construcción de memoria sobre los acontecimientos, biografías y testimonios del archivo.

d) Una conformación geográfica singular que puede expresarse de múltiples formas, siendo una de ellas la de un territorio de memoria.

\section{Los (des)bordes del archivo Carri}

A partir de Los Rubios, Albertina habilitó una superficie de memoria con múltiples puntos de entrada. ${ }^{4}$ Sobre ella, se inscribieron una serie de escenas e imágenes afectivas que tensionaron numerosos relatos y saberes sobre la militancia de los años

4 La propuesta metodológica del archivo afectivo fue desarrollada en Saporosi ("La experiencia del amor"). La construcción de escenas es una de las operaciones metodológicas de esta modalidad del archivo que se configura a partir de la práctica del montaje (Benjamin; Didi-Huberman, Cuando las imágenes) y de la lectura obstinada (Farge). Las otras operaciones son aquellas que surgen del análisis de las lógicas de aproximación y de oposición (Farge) y de la hermenéutica (Gadamer, Ricoeur, Oberti y Pittaluga). 
setenta, pero, sobre todo, revitalizaron una mirada singular y generacional de cómo construir sentido sobre el pasado de violencia; un intento de producir una imagen justa, siguiendo a Ana Amado, o en otras palabras, una ética de la memoria.

Con el cortometraje Restos (2010), la instalación Operación Fracaso y el sonido recobrado (2015) y el documental Cuatreros (2017) se pueden configurar dos nuevas escenas a esta superficie.

\section{La escena de la materialidad fílmica o found footage}

Las tres intervenciones estéticas de Albertina Carri proponen una reflexión sobre la materialidad concreta de la imagen fílmica.

En el caso de Restos, la pregunta se orienta específicamente por el metraje $\mathrm{e}^{5} \mathrm{del}$ "cine militante" (así lo denomina la voz de Analía Couceyro, interpretando el guion de Marta Dillon) de los años sesenta y setenta, y se entronca con una enunciación visual que explora la acumulación, la manipulación y la desintegración de ese mismo material. Los paneos lentos, en plano detalle, recorriendo cuidadosamente las latas de celuloide corroídas por el paso del tiempo y por las marcas de la violencia evidencian, más que una fragilidad del material, un atisbo de resurrección de sus condiciones de supervivencia. Las ínfimas partículas que lo conforman se ven manipuladas hasta su composición celular con el objetivo de mostrar los vestigios de su derrotero histórico y de su desaparición. "El fulgor de su ausencia quema, ahora mismo", clama Couceyro, mientras el ardor del material se consume hasta sus cenizas, que luego se traducen en sobreimpresiones en una pantalla oscura.

Se encuentra allí ese intento por configurar una representación justa que permite captar la complejidad de la "cámara como arma" en una doble operación: por un lado, quemar el material invoca una forma de evidenciar las cenizas que ha dejado la censura y la represión; y por el otro, constituye la reminiscencia, o "el gesto desafiante", de una potencia vital que pretende "mellar la trama que cubre el cielo de los rebeldes" (Carri, Restos).

En efecto, Carri visibiliza el soporte técnico de la materialidad de la memoria y ubica la pregunta por cómo interpretar toda esa acumulación de metraje fílmico de cine político militante en el marco de una escena histórica que, efectivamente, ha cambiado pero que sigue siendo motivo de discusiones y reflexiones contemporáneas. Esas películas, que han sido ultrajadas, sustraídas, guardadas en fragmentos, mantienen en su registro las marcas de su producción y circulación (nombres falsos, latas en condiciones ruinosas, sustracciones de secuencias, entre otras). Esa práctica de archivo conforma una poética del registro que vuelve disponible, en un doble movimiento, un acervo de imágenes que se creían destruidas, pero, que también requieren de su consignación, de su interpretación. La doble función derrideana.

5 El nombre técnico que se le asigna a este tipo material es el de "metraje encontrado" o found footage. 
Esta exploración de la biografía personal se desarrolla en el marco de una tarea de reconstrucción — casi interminable - de un archivo visual sobre los años setenta. En ese permanente ensamblado de imágenes y materialidad emerge el vacío, la hoja en blanco sobre donde inscribir la búsqueda filial, personal y generacional. Esta escena de la materialidad fílmica se ve también nutrida por las intervenciones de Operación Fracaso y, sobre todo, por el registro audiovisual en Cuatreros.

Operación Fracaso y el sonido recobrado configura una intervención audiovisual desplegada en cuatro territorios: Investigación del cuatrerismo, Cine puro, Allegro-A piacere y Punto impropio. Específicamente, las secciones Cine puro y Allegro-A piacere siguieron la línea de indagación sobre el found footage y la materialidad sensible del dispositivo cinematográfico. El territorio Punto impropio estuvo destinado a un acercamiento singular con su madre, intentando revitalizar esa mirada amorosa sobre su biografía, inicialmente construida en Los Rubios, y el sitio Investigación del cuatrerismo fue aquel dedicado a su padre y el punto inicial del filme Cuatreros.

Este documental estrenado en 2017 construye una genealogía político-intelectual que intenta rastrear la relación entre Roberto Carri, el bandolero rebelde Isidro Velázquez y el director de cine Pablo Szir. Albertina indaga en el modo en que estos tres personajes se traman a partir de sus prácticas políticas, intelectuales y artísticas: Roberto Carri escribió un clásico texto sobre el bandolero correntino conocido como Isidro Velázquez: formas prerrevolucionarias de la violencia y Szir filmó una película sobre ese libro. Tanto Roberto Carri como Pablo Szir fueron secuestrados durante la dictadura e integran la lista de detenidos desaparecidos. La película se asume como una escena de contacto entre textos, imágenes y personajes ausentes, víctimas de las diferentes formas de la represión estatal. En este sentido, Cuatreros expresa la posibilidad de darle imagen a esa zona sustraída de la filiación político-intelectual y de otorgarle un estatuto de representación capaz de dislocar su propia constitución en pleno acto fílmico.

Es un filme que se compone de la sucesión de fragmentos audiovisuales provenientes de películas amateurs, noticieros, publicidades de los años sesenta y documentales políticos, rigurosamente articulada con la voz en off de la narradora a lo largo del todo el filme y bajo un mismo tono. Por momentos, la imagen se subdivide en partes y cada una de ellas expone un material diferente, descentrando la percepción del acto de ver.

El único episodio escenificado por Albertina Carri es el plano secuencia final que muestra un momento amoroso con su hijo, utilizando una exposición de contraste y un juego lumínico sensible.

El trabajo con los materiales en Cuatreros se asemeja a la tarea documental del cineasta ruso Dziga Vértov, quien consideró a ese tipo de documentos como "ruinas" de la modernidad y como materiales sin terminar, incompletos e informes. Carri, en resonancia con esta percepción, admite que ese metraje filmado ya ha sido montado con otros propósitos mediático-políticos, de modo que su intervención se orienta a llevar adelante un proceso de deconstrucción de las mismas imágenes y a desarrollar un nuevo ensamblado sobre otras series de sentido. Esa es también la propuesta del 
Kino-Pravda (Cine Verdad) de Vértov, a través de la metodología del "Cine-ojo": un cine cuya verdad no está en el material rodado sino en el montaje de esos documentos. Así lo resume el autor:

[En primer lugar], el Cine-ojo, amenazando la representación visual del mundo hecha por el ojo humano y ofreciendo su propio "Veo"; y, [en segundo lugar] el Kinok-montador, organizando los minutos de la estructura vital, vista de ese modo por primera vez (22).

Según la perspectiva de Albertina Carri, las imágenes ofrecen sus propios actos de ver (Didi-Huberman, Lo que vemos), de manera tal que desplazan el principio mismo de la representación visual y promueven una forma del cine que opera como instante de verdad a través del montaje expresivo. En ese sentido, se inscribe en una experiencia vital que promueve un modo de escritura novedoso ("modo de vista por primera vez") sobre esos documentos del mundo.

A diferencia de la tarea de Sergei Eisenstein, cuya forma del montaje operaba mediante el choque y la discontinuidad, Carri construye una práctica más asociada al contacto, al roce y al encuentro entre documentos que no apunta solamente a generar un impacto visual o psicológico, sino a producir un acontecimiento a partir de múltiples actos de ver que no necesariamente interrumpen un flujo dramático. Aquí, el montaje, como sugiere Vértov, asume un modo de exposición que evidencia el desplazamiento de los fundamentos de la representación de los registros audiovisuales sobre los acontecimientos históricos y habilita la construcción de ciertas escenas de interpretación sobre el pasado.

Por tanto, la doble operación del montaje (deconstructiva y de reensamble) reconfigura los parámetros temporales y las zonas de contacto de/entre los materiales. Y esta práctica implica asumir que los documentos de la historia desbordan los sentidos posibles de su consideración meramente historiográfica o meramente estética y habilita la posibilidad de encontrar nuevos entramados de significación en el cruce de ambas.

\section{La escena del territorio de memoria}

Dada su especificidad, la instalación Operación Fracaso nos permite considerar una segunda escena en esta construcción del archivo. Partimos de una concepción de la memoria comprendida como una "escena de contacto"6 con el pasado que, en su

6 La noción de memoria como escena de contacto está inspirada en los aportes de Ahmed. La autora desarrolla la categoría "escritura de contacto". Afirma: "Al hacer 'escritura de contacto' o escribir sobre el contacto no sólo entretejo lo personal y lo público, lo individual y lo social, sino que muestro las maneras en las que estos ámbitos adquieren forma a través de los demás, o incluso cómo se dan forma uno a otro. Así que no es que mis 'sentimientos' estén en la escritura, aunque por toda mi escritura están regadas historias de cómo mi contacto con los demás me da forma" (42).

La noción de memoria como escena de contacto se fundamenta en la idea de que la dimensión de los afectos puede operar como un vector de memoria capaz de configurar una forma singular de comprender y elaborar las expe- 
misma configuración, habilita la construcción de "mapeos afectivos" (Flatley), de recorridos por espacios públicos, acercamientos a objetos y recuerdos de la infancia y/o expresiones comunitarias de duelo. De este modo, se asume que esta experiencia de memoria explora modalidades de intervención que trascienden la mera narratividad de la rememoración y se configuran en torno a un modo de la experiencia dentro de la comunidad, donde las dimensiones afectivas y corporales se asumen como centrales.

Ludmila da Silva Catela propone pensar los archivos como territorios de memoria, inspirada en una lectura crítica sobre la obra de Pierre Nora. Un territorio de memoria, más que un lugar de memoria, refiere a

las relaciones o al proceso de articulación entre los diversos espacios marcados y las prácticas de todos aquellos que se involucran en el trabajo de producción de memorias sobre la represión; resalta los vínculos, la jerarquía y la reproducción de un tejido de espacios que potencialmente puede ser representado por un mapa, donde situamos el territorio. Al mismo tiempo, las propiedades metafóricas del territorio nos permiten asociar conceptos tales como conquista, litigio, desplazamiento a lo largo del tiempo, verdad de criterios de demarcación, de disputas, de legitimidades, de "soberanías" (22).

Siguiendo estas consideraciones, podemos pensar a Operación Fracaso como la expresión de un territorio de memoria.

Las diferentes secciones de la instalación invitan a la audiencia a transitar y a habitar las diferentes capas de la memoria de Carri. En la medida en que son experimentadas se explora una articulación posible entre su historia personal y el contexto político en la Argentina durante los años setenta. Los territorios construyen una serie de paisajes multisensoriales desplegando la materialidad del celuloide por diferentes zonas de la instalación y una proliferación de visualidades por diferentes pantallas de televisores de tubo. Atravesar esos espacios, rodeados de objetos personales, revitaliza el modo en que el metraje fílmico constituye una parte fundamental de su escena de memoria. Asimismo, la permanente proyección de imágenes ${ }^{7}$ es interrumpida por la lectura de cartas de su madre, escritas desde el Centro Clandestino de Detención "Sheraton" y enviadas a Albertina y sus hermanas cuando eran niñas.

La proliferación de información, documentos y registros visuales ponen de relieve las implicancias del dilema de Foucault o del mal de archivo de Derrida, conjugados, en este caso, con las marcas históricas de los años de insurgencia y radicalización política en Argentina. Esta escena, que se construye en el marco del archivo afectivo y se experimenta in situ, articula enojos, dolores y preguntas irresueltas, con situaciones

riencias límites del pasado. Los afectos, siguiendo a Sara Ahmed, más que instancias primarias de autenticidad, son producto del contacto que las subjetividades y los grupos sociales construyen y experimentan con los entramados normativos, culturales y sociales en un determinado momento histórico.

7 Estas se conforman de noticieros, telenovelas y películas de los años sesenta y setenta que, como se dijo, constituyen también el origen del filme Cuatreros. 
placenteras y amorosas sobre su pasado, lo que pone en evidencia la mirada compleja y profunda sobre la militancia de sus padres.

En el catálogo de la instalación Marta Dillon recuperó esta modalidad del archivoterritorio y focalizó en la experiencia de crear y transitar esos espacios (im)propios de la memoria como dispositivos comunitarios de comprensión y elaboración de las pérdidas. Afirma:

Caminamos tomadas de la mano cruzando el manto verde del parque, sintiendo sin mirar en la retina el brillo del río que platea con la luz de una mañana que empieza a desarmarse en mediodía. No respetamos los caminos marcados, ella me conduce en silencio, no hablamos ni siquiera cuando los muros del cenotafio nos envuelven con su abrazo helado y atisbamos de reojo los nombres de los nuestros. Siempre los encontramos, unos nombres que se acumulan sobre otros y debajo de otros, una tajada inmóvil cortada con filo irregular al discurrir del tiempo. En esta fecha y a esta edad, estos fueron quitados de la vida. Carri y Caruso, azar de abecedario, la pareja permanece unida. Ya no los mencionamos, no hace falta, hemos pasado tantas veces por esos nombres que nos habitan y nos siguen allí donde vamos.

En suma, la experiencia de caminar y habitar la instalación, en el contexto de un territorio más amplio - El parque de la memoria - se convierte en una escena afectiva de carácter público que permite reinterpretar los materiales del pasado en una cadena de sentidos diferente.

\section{Palabras finales}

Las discusiones por la epistemología de la noción de archivo nos han permitido construir una genealogía pertinente para elaborar una comprensión específica sobre las prácticas poético-testimoniales de hijos e hijas de militantes y, particularmente, sobre las tres intervenciones analizadas de Albertina Carri. Las escenas aquí presentadas contribuyen a configurar una tarea archivística particular, en donde la experiencia, el contacto y la materialidad se conjugan de manera ineludible en la construcción de memoria de la autora. Un archivo afectivo, tal como ha sido planteado, admite una variedad de documentos y de objetos que trascienden la mera capacidad de repositorio o registro; asume, también, la posibilidad de que experiencias e intervenciones de distinto orden pueden ser parte de esta modalidad. En efecto, el modo en que estas ingresan al registro puede pensarse a través de la idea de territorio de memoria que, entre otras cuestiones, permite desdibujar los límites de ese archivo.

Volviendo a las preguntas iniciales del trabajo, resulta pertinente recuperar la revisión de la condición de lo inimaginable y de lo irrepresentable en el marco de un archivo afectivo. Como propone Didi-Huberman (Imágenes pese a todo), la relación 
entre este tipo de imágenes y los acontecimientos históricos sugiere un "territorio incompleto, de supervivencia, fragmentario; pero este territorio, desde luego, existe" (43). No solo existe, sino que también evidencia una posibilidad de volverse imagen y darse a ver. Esta representación de lo posible implica un desplazamiento de sus principios absolutos y un gesto que hace fracasar el canon de lo representativo: aquel que considera a la representación en términos miméticos y, también, aquel que reniega de cualquier instancia de sedimentación sobre los soportes visuales o discursivos. En ambos casos, el concepto de realidad se presenta problemático e incapaz de asumirse analíticamente.

Si la representación implica un desplazamiento, este se asume como un movimiento situado, condicionado por el devenir de la historia y su correlación de fuerzas sociales, y como un movimiento inmanente de la experiencia misma de la producción social.

Pero también, este modo de acumular, exponer y habitar estos documentos históricos y personales permite revitalizar la condición ética de tal producción. La operación de este montaje de documentos heterogéneos, tanto en una instalación como en un filme documental, constituye una tarea restituyente que implica un "acto de justicia” en relación con un proceso de construcción de sentidos sobre la desaparición forzada, sobre el dolor y las experiencias límite del pasado. Si el testimonio nos obliga a trabajar en el seno mismo de la palabra, la imagen, por su parte y como sugiere Didi-Huberman, nos obliga a trabajar en el seno mismo de la representación, por más fragmentada o ruinosa que se presente. Su condición de vestigio no le quita su instante de verdad. Por tanto, si la relegamos al territorio de lo impensado se corre el peligro de desligarse de la responsabilidad que el problema ético suscita, precisamente porque si una desaparición fue posible, fue también porque fue pensable. ${ }^{8}$

\section{Referencias}

Ahmed, Sara. La política cultural de las emociones. México D. F., PUEG, 2015.

Amado, Ana. La imagen justa. Buenos Aires, Colihue, 2009.

Castro, Eduardo. El vocabulario de Michel Foucault. Un recorrido alfabético por sus temas, conceptos y autores. Bernal, Universidad Nacional de Quilmes, 2004.

Carri, Albertina. "Las vasijas destrozadas”. Página 12 [Argentina]. 10 mar. 2010. Disponible en: https://www.pagina12.com.ar/diario/suplementos/radar/subnotas/6511-1231-2010-10-03.html

Cvetkovich, Ann. An Archive of Feelings: Trauma, Sexuality, and Lesbian Public Cultures. Durham, Duke University Press Books, 2003.

8 Didi Huberman recupera al historiador Vidal Naquet en este aspecto: "No puede [el/la historiador/a], no debe admitir que nos quitemos de encima el problema planteado por el genocidio de los judíos relegándolo a la categoría de lo impensable. El genocidio fue pensado, por lo tanto, era pensable" (Vidal Naquet 7, cit. en Didi-Huberman, Imágenes pese a todo 48). 
Da Silva Catela, Ludmila. Los archivos de la represión: Documentos, memoria y verdad. Buenos Aires, Siglo xxi, 2002.

Derrida, Jacques. Archive Fever. Madrid, Trotta, 1997.

Didi-Huberman, Georges. Lo que vemos. Lo que nos mira. Buenos Aires, Manantial, 1997.

- - Imágenes pese a todo. Buenos Aires, Paidós, 2004.

- - Cuando las imágenes toman posición. Madrid, A. Machado Libros, 2008.

Dillon, Marta. "Presente". En catálogo de Operación Fracaso y el Sonido Recobrado, 2015.

Farge, Arlette. The Allure of the Archives. Valencia, Editorial Institució Alfons El Magnànim, 1989.

Flatley, Jonathan. Affective Mapping. Melancholia and the Politics of Modernism. Londres, Harvard University, 2008.

Foucault, Michel. La arqueología del saber. Buenos Aires, Siglo xxi, 2011.

Foster, Hal. "An archival impulse". October, n. ${ }^{\circ}$ 110, 2004, pp. 3-22.

Gadamer, Hans-Georg. El giro hermenéutico. Madrid, Cátedra, 1990.

Guasch, Ana María. Arte y archivo, 1920-2010. Genealogías, tipologías y discontinuidades. Madrid, Akal, 2011.

Nora, Pierre. "Introducciones”. Les Lieux de Mémoire. París, Gallimard, 1984.

Oberti, Alejandra y Roberto Pittaluga. Memorias en montaje. Buenos Aires, El cielo por asalto, 2006.

Ricoeur, Paul. La memoria, la historia, el olvido. Buenos Aires, Fondo de Cultura Económica, 2000.

Saporosi, Lucas. "Implicancias epistemológicas y reflexiones metodológicas en torno a la construcción de un archivo afectivo". Crítica Contemporánea. Revista de Teoría Política. Dossier "Sentir la política: la relevancia de las emociones para la vida política contemporánea”, Universidad de la República en Montevideo, 2017. Disponible en: http://www.criticacontemporanea.org/2017/12/este-anola-revista-contiene-dos.html

- - " "La experiencia del amor en las producciones estéticas de hijos e hijas de militantes detenidos/as desaparecidos/as: La construcción de un archivo afectivo". Tesis para optar al grado de Magíster en Historia y Memoria. Memoria Académica, Universidad Nacional de La Plata, Facultad de Humanidades y Ciencias de la Educación, 2018. Disponible en: http://www.memoria.fahce.unlp.edu.ar/tesis/ te.1581/te.1581.pdf

Vértov, Dziga. "Kinoks: A revolution”. Kino-eye. The Writings of Dziga Vertov. California, University of California Press, (1923) [1984].

Enviado: 7 de agosto de 2019

Aceptado: 24 de abril de 2020 